\title{
PANTUN PADA SENI PERTUNJUKAN DALAM ADAT PERNIKAHAN DI KECAMATAN KAUR SELATAN KABUPATEN KAUR
}

\author{
Changga, Sarwit Sarwono, dan Agus Joko Purwadi \\ Program Studi Pendidikan Bahasa Indonesia \\ Jurusan Pendidikan Bahasa dan Seni \\ FKIP Universitas Bengkulu \\ Pawjaguar71@gmail.com
}

\begin{abstract}
Abstrak
Tujuan penelitian ini untuk mendeskripsikan proses, fungsi, dan makna pantun bersahut dalam seni pertunjukan adat pernikahan di Kecamatan Kaur Selatan. Jenis penelitian ini adalah penelitian kualitatif, sedangkan metode yang digunakan adalah metode etnografi. Data penelitian ini didapat dari pengamatan langsung, dokumentasi, dan wawancara secara mendalam kepada informan. Dari hasil analisis yang dilakukan terhadap tradisi pantun bersahut, dalam penyelenggaraannya pantun bersahut diiringi dengan tarian mainang dan irama musik yang mengiringi tarian dan irama pantun yang diucapkan, adapun judul irama musik yang sering digunakan dalam pantun bersahut ini ialah yang pertama irama pembuka (1) Sumpaya, (2) Mainang Sayang, (3) Pulau Pinang, (4) Serawak, (5) Jali-jali, (6) Rembang Petangh,(7) Cerai kasih, (8) Bunga Mawar, dan penutup (9) Dayung Pariaman. Pada prinsipnya ini disajikan saat malam hari, warga dan perangkat desa setempat menyebutnya sebagai malam mainangan atau inai curi, dimana malam tersebut dilakukan khusus untuk tradisi pertunjukan pantun bersahut. Tradisi ini dilakukan setelah melalui proses lamaran, serah terima hantaran, dan akad nikah, belaak dan pengantin besanding. Makna teks dan konteks yang terkandung di dalam tradisi pantun bersahut mainangan ini adalah agar kita selalu beradab dalam kehidupan bersosial dan bermasyarakat serta terlebih lagi dalam berkomunikasi yang baik dan sopan dalam penggunaan bahasanya.
\end{abstract}

\section{Kata Kunci: Pantun, Tradisi Mainangan, Kaur}

\begin{abstract}
The purpose of this study is to describe the process, function and meaning of the rhyme that is in the traditional performing arts of marriage which takes place in South Kaur District. This type of research is qualitative research, while the method used is ethnographic method. The data in this study are in the form of results from direct observations in the research environment, from the results of documentation, and indepth interviews with informants about the rhyme that is spoken in traditional marriage in South Kaur District. From the results of the analysis carried out on the tradition of the rhyme, the implementation of the rhyme is accompanied by a dance and rhythm of the music that accompanies the dance and the rhythm of the rhyme that is spoken, while the rhythm of the music that is often used in the rhyme is the first opening rhythm, (1) Sumpaya, (2) Mainang Sayang, (3) Pulau Pinang, (4) Serawak, (5) Jali-jali, (6) Rembang Petangh, (7) Divorce, (8) Rose Flower, and (9) the cover of Paddle
\end{abstract}


Pariaman. In principle, this is served at night when local residents and village officials call it the night of playing or stealing, where the night is carried out specifically for the tradition of the rhyming performances. This tradition is done after going through the application process, delivery handover, and marriage contract, martial arts and brides besanding. The meaning of the text and the context contained in the tradition of the rhyme-friendly rhyme is so that we always face in the life of socializing and socializing and moreover in communicating well and politely in the use of the language.

\section{Keywords: Pantun, Play Tradition, Kaur}

\section{PENDAHULUAN}

Berdasarkan informasi yang didapatkan oleh peneliti di website resmi Kabupaten Kaur (www.kaurkab.go.id) Kabupaten Kaur memiliki 15 Kecamatan, 192 desa, dan 3 kelurahan. Adapun 15 Kecamatan ini terdiri dari Nasal, Maje, Kaur Utara, Kaur Selatan, Tetap, Luas, Muara sahung, Semidang Gumay, Kinal, Tanjung Kemuning, Kelam Tengah, Lungkang Kule, Padang Guci Hulu, dan Padang Guci Hilir. Masyarakat yang tinggal di Kabupaten Kaur membentuk kelompok masyarakat adat. Kelompok tersebut adalah masyarakat Suku Semende Nasal, Semende Ulu Nasal, Semende Banding Agung, Semende Muara Sahung, Semende Kaur Tanjung Agung, Marga Sambat, dan Suku Kaur Nasal. Berbagai kelompak adat di Kabupaten Kaur ini kemudian berkembang dalam Suku Kaur, mayoritas masyarakat Suku Kaur pada umumnya bermata pencaharian sebagai menggarap pesawangan dengan menggarap padi. Selain itu juga, aktivitas budaya yang juga sering dilakukan masyarakat Kabupaten Kaur ini juga dilakukan seperti aktivitas pernikahan, aktivitas menampilkan seni pertunjukan dan sebagainya yang merupakan kebiasankebiasaan menjadi ciri dan tradisi kolektifnya.

Dalam halnya mengenai tradisi adalah informasi yang diteruskan dari generasi ke generasi baik tertulis maupun lisan, karena tanpa adanya ini, suatu tradisi dapat punah. Dalam tradisi lisan adalah folklor yang bentuknya memang murni lisan, bentuk-bentuk folklor yang termasuk ke dalam kelompok besar ini antara lain puisi rakyat seperti pantun, gurindam, dan syair (Rafiek, 2012:52-53).

Pantun sebagai salah satu bentuk sastra lisan, secara luas dikenal di tanah air kita ini, merupakan kebudayaan yang lahir dari masyarakat Melayu. Beberapa keistimewaan pantun dibandingkan dengan puisi rakyat yang lain yaitu pantun relatif lebih mudah ditangkap maknanya. Dengan demikian pantun merupakan salah satu alat yang paling efektif dalam mengungkapkan perasaan. Di samping itu berupa mainangan atau disebut dengan pantun bersahut yang ditampilkan pada tarian mainang yang terdapat di Kecamatan Kaur Selatan ini merupakan tradisi lisan dimana kedua belah pihak atau lebih saling bersahut atau berbalas pantun dari proses mainang ditampilkan dengan maksud dan tujuan tertentu. Menurut Danandjaja (1994:5), tradisi lisan hanya mencangkup cerita rakyat, teka-teki, peribahasa, dan nyanyian rakyat.

Tradisi lisan berupa berbalas pantun atau pantun bersahut yang terdapat pada kesenian mainang di Kecamatan Kaur Selatan merupakan acara yang wajib ditampilkan setiap berlangsungnya adat pernikahan antara pihak mempelai perempuan sebelum acara pernikahan ataupun bersanding di pelaminan, tradisi 
lisan ini masih dilakukan pada adat pernikahan di Kecamatan Kaur Selatan ini.

Perkembangan tradisi lisan pantun bersahut di Kecamatan Kaur Selatan yang ada pada seni pertunjukan ini sekarang sudah berkurang dalam pemakaiannya, karena budaya masyarakat sekarang merasa bahwa bila menggunakan tradisitradisi tersebut terlalu banyak mengeluarkan uang dan perubahan selera masyrakat sudah berubah karena yang kita sayangkan bahwa tradisi lisan pantun bersahut dalam seni pertunjukan adat pernikahan tersebut merupakan warisan budaya yang mengandung nilai-nilai budaya, dan makna yang disampaikan yang harus dipertahankan oleh masyarakat kolektif itu sendiri terutama masyarakat di Kecamatan Kaur Selatan Kabupaten Kaur.

Peneliti berharap dengan adanya penelitian tersebut agar dapat menghimbau kepada masyarakat luas supaya kita dapat menjaga dan melestarikan tradisi lisan yang diajarkan di daerah masing-masing salah satunya itu pantun bersahut pada seni pertunjukan yang ditampilkan dalam adat pernikahan di Kecamatan Kaur Selatan. Serta peneliti juga dapat mengetahui sejarah mengenai tradisi lisan pantun bersahut pada adat pernikahan di Kecamatan Kaur Selatan. Maka dari itu dalam penelitian ini peneliti mengangkat permasalahan pantun pada seni pertunjukan dalam adat pernikahan di Kecamatan Kaur Selatan Kabupaten Kaur. Hal ini juga sebuah tanggung jawab bagi penulis sesuai dengan bidang ilmu yang ditekuni yaitu sebagai bentuk pemertahan budaya folklor Indonesia.

\section{METODE}

Metode penelitian yang digunakan dalam penelitian ini adalah metode penelitian kualitatif etnografi.

penelitian yang dilakukan di Desa Pasar Lama, Desa Air dingin, Desa Jembatan Dua Kecamatan Kaur Selatan Kabupaten Kaur. waktu penelitian yang dilaksanakan pada bulan Maret s.d.April 2018 dengan cara mengamati tradisi pantun bersahut yang ditampilkan dan mewawancarai informan yang memahami betul mengenai tradisi pantun bersahut dalam adat pernikahan di Kecamatan Kaur Sealatan.

Data dalam penelitian ini adalah berupa hasil dari pengamatan langsung pada lingkungan penelitian, dari hasil dokumentasi, dan wawancara secara mendalam kepada informan mengenai pantun bersahut yang dituturkan pada adat pernikahan di Kecamatan Kaur Selatan.

Sumber data dalam penelitian ini adalah pengamatan langsung, wawancara informan yang memahami betul mengenai tahapan, fungsi, dan makna dari tradisi lisan pantun bersahut pada adat pernikahan di Kecamatan Kaur Selatan. Teknik pengumpulan data yang digunakan dalam penelitian ini adalah observasi, wawancara, catatan langsung, dan dokumentasi. Analisis data dengan langkah (i) peneliti mentranskripsikan data yang didapatkan dari hasil lapangan maupun hasil rekaman dan wawancara informan, (ii) Selanjutnya peneliti melakukan identifikasi data, (iii) Peneliti melakukan klasifikasi data, dari hasil wawancara, observasi yang telah diperoleh dengan melakukan pemilahan, pemeriksaan, pembandingan, dan pengkategorian data sesuai dengan permasalahan yang dibahas. (iv) Peneliti mendeskripsikan tahapan-tahapan dan fungsi dari tradisi pantun bersahut. (v) Peneliti melakukan verifikasi data hasil wawancara, (vi) peneliti melakukan identifikasi makna-makna. (vii) Peneliti melakukan analisis makna-makna yang ditemukan dalam tradisi pantun bersahut adat pernikahan di Kecamatan Kaur Selatan, (vii) Mendeskripsikan hasil penelitian dalam bentuk narasi. (ix) membuat kesimpulan 


\section{HASIL PENELITIAN DAN PEMBAHASAN}

Mengenai catatan tradisi pantun bersahut adat pernikahan di Kecamatan Kaur Selatan kalangan masyarakat yang mengundang grup pantun bersahut atau tradisi malam mainangan ini sudah jarang dilakukan oleh kalangan keluarga yang ingin mengadakan kegiatan tersebut. Ada beberapa faktor yang membuat tradisi mainangan ini jarang dilakukan, diantaranya yang membuat kegiatan ini sudah jarang digunakan karena biaya dari grup yang mengadakan terlalu tinggi. Adapun perubahan yang terjadi dalam tradisi pantun bersahut mainang ini sesuai dengan tuntunan zaman yang semakin maju seperti halnya tradisi berbalas pantun ini dahulunya dimulai pada tahun 1980-an dan bentuk operasionalnya sudah mengalami perubahan pada waktu dahulu kegiatan pantun bersahut ini dimulai dari jam 20.00 WIB selesai pada jam 03.00 WIB malam dan sekarang pelaksanaannya sudah di potong dari jam 20.00 WIB sampai jam 23.30 WIB dikarenakan waktu yang telah ditetapkan oleh peraturan pemerintah daerah dengan alasan kenyaman dan keamanan, dan juga alat-alat musiknya sekarang sudah dibantu dengan organ tunggal sehingga penggunaannya menjadi praktis namun, adat dan ketentuannya masih menggunakan cara yang lama.

Tradisi malam mainangan atau pantun bersahut ini dilakukan oleh anggota grup mainangan sendiri yang terdiri 16 orang laki-laki yang sudah dibagi dari semua anggota grup pantun bersahut mainang ini semuanya akan membawa pantun dan tarian dengan diiringi irama musik. Adapaun, alat-alat musik yang digunakan dalam pantun bersahut ini terdiri dari, gendang penabu, kerincing, dan piano dari orgen tunggal, setiap macam anggota grup mainang memiliki tugas dan peran masingmasing yang sudah diundang oleh ahli rumah acara. Tradisi malam mainangan ini di mulai pada malam hari pukul 20.00 WIB kegiatan ini dilakukan sesudah acara pengantin belaak, adapun ketua adat desa menyebut malam mainangan ini dinamakan malam inai curi, malam pengantin bercampur atau bujang gadis bercampur para anggota grup mainangan memilki cara khas berpakaian adat yaitu.

Menggunakan kostum jas hitam, kopiah hitam, serta memakai kain sarung yang diikat pada pinggang pemeran. Dalam penyelenggaraannya pantun bersahut ini diiringin dengan tarian mainangan dan irama musik tersebut mengiringi tarian dan pantun yang diucapkan, adapun judul irama musik yang sering digunakan dalam pantun bersahut ini ialah yang pertama irama pembuka, Sumpaya, Mainang Sayang, Pulau Pinang, Serawak, Jali-Jali, Rembang Petang, Cerai Kasih, Bunga Mawar, dan penutupnya Dayung Pariaman, dari ke-9 irama ini dibawakan tergantung dari ahli rumah apa ingin disajikan semua dalam berbalas pantun atau tidak.

Secara kronologis aktivitas pertunjukan berbalas pantun ini dilakukan sebagai berikut:

\section{Irama Sumpaya}

Dalam tradisi pantun bersahut irama musik pembuka yaitu sumpaya, irama musik sumpaya ini terdiri 4 orang penari sekaligus pembawa pantun, 4 orang laki-laki penari sumpaya ini dibagi menjadi 2 kelompok dalam tariannya penari membawa saputangan adapun teks pantun yang digunakan dalam tarian sumpaya ini.

Penari pertama berpantun sesuai dengan irama musik sumpaya pemeran pertama membuka pantun.

Setelah diucapkan pantun dari pemeran pertama selanjutnya pantun tersebut dibalas oleh pemeran penari kedua dengan irama yang serupa.

\section{Irama Mainang Sayang}

Ketika irama Mainang Sayang ini dimainkan pemeran penari terdiri dari 2 
orang penari sekaligus pembawa pantun bersahut, adapun 2 orang laki-laki penari Mainang Sayang ini penari pertama memakai selendang kainnya dikembangkan, dan penari kedua hanya menari memakai jas hitam.

Penari pertama memakai jas hitam berpantun sesuai dengan irama musik Mainang Sayang adapun pantun yang diucapkan dari pemeran pertama.

Kemudian setelah diucapkan oleh pemeran pertama tadi selanjutnya pemeran kedua yang memakai kain selendang membalas pantun yang diucapkan oleh lawannya tadi.

\section{Irama Pulau Pinang}

Pada irama Pulau Pinang ini dimainkan pemeran penari terdiri 2 orang sekaligus pembawa pantun, dalam irama Pulau Pinang ini penari pertama membawa payung yang dikembangkan dan penari kedua membawa kain yang di kembangkan.

Penari pertama yang membawa payung ini membuka pantun sesuai dengan irama musik Pulau Pinang adapun pantun yang diucapkan.

Sesudah pemeran pertama mengucapkan pantun, kemudian pemeran kedua yang memakai kain membalas pantun dari pemeran pertama.

\section{Irama Serawak}

Pada irama musik Serawak ini pemeran pantun mainang ini terdiri 4 orang laki-laki pemeran pantun bersahut dan dibagi menjadi 2 kelompok dari ke 4 orang pemeran pantun bersahut tersebut mereka memakai jas hitam semua. Adapun, pantun yang diucapkan dari 2 orang kelompok pertama penari yang memakai jas hitam dengan mengikuti irama Serawak.

Selanjutnya setelah pantun itu diucapkan oleh kelompok pertama, pantun tersebut dibalas oleh kelompok kedua dengan nada irama musik Serawak yang sama adapun pantun yang dibalas.

\section{Irama Jali-jali}

Pada irama Jali-jali ini dimainkan pemeran pantun bersahutnya terdiri 2 orang pemain pantun, 2 pemain pantun bersahut pada irama Jali-jali tersebut membawa kain selendang. Adapun, pantun yang di ucapkan oleh pemain pertama yang menggunakan kain selendang pada irama musik Jali-jali .

Selanjutnya setelah pantun tadi disampaikan oleh pemeran pertama, pemeran kedua membalas pantun dari pemeran pertama tadi dengan irama Jali-jali adapun pantun yang diucapkan dari pemeran kedua tersebut.

\section{Irama Kembang Petang}

Pada irama Kembang Petang ini pemeran pantun bersahut terdiri 2 orang pemain, 2 pemeran pantun bersahut pada irama kembang petang ini menggunakan kain yang diikat dipinggang. Adaupun, pantun yang digunakan pada pemeran pertama pada irama Kembang Petang.

Selanjutnya pantun tersebut dibalas oleh pemeran kedua dari irama Kembang Petang adapun pantun dibalas tersebut.

\section{Irama Cerai Kasih}

Pada irama Cerai Kasih ini pemeran pantun bersahut terdiri 4 orang dibagi menjadi 2 kelompok, ke 4 orang pemeran pantun bersahut tersebut 2 orang memegang kain 2 orang lagi hanya memakai jas hiitam.

Adapun, pantun yang diucapkan dari kelompok pertama ini dengan Irama Cerai Kasih.

Selanjutnya sesudah pantun tadi diucapkan oleh kelompok pertama maka kelompok kedua membalas pantun tersebut.

\section{Irama Bunga Mawar}

Pada irama Bunga Mawar ini pemeran tradisi pantun bersahut terdiri 6 
orang pemeran, dari 6 orang pemeran pantun bersahut pada irama Bunga Mawar ini 6 orang tersebut memegang 1 tangkai bunga mawar, dari pemeran 6 orang ini di bagi menjadi 3 kelompok. Adapun, pantun yang diucapkan oleh pemeran kelompok pertama irama Bunga Mawar.

Selanjutnya pemeran kelompok kedua membalas pantun yang sudah diucapkan oleh pemeran pertama tadi. Adapun pantun yang diucapkan oleh pemeran kelompok kedua.

Selanjutnya kelompok ketiga membalas pantun yang diucapkan oleh kelompok kesatu dan dua adapun pantun yang diucapkan oleh kelompok ketiga.

\section{Irama Dayung Pariaman}

Di penghujung pertunjukan pantun bersahut mainang ini adapun irama penutup dari pantun bersahut ini ialah irama Dayung pariaman, adapun pemeran pantun dari Dayung Pariaman ini terdiri dari 2 orang pemain, pemeran pertama menggunakan satu payung dan pemeran kedua memegang kain.

Adapun pantun yang diucapkan oleh pemeran pertama dayung pariaman.

Selanjutnya pemeran kedua membalas pantun oleh pemeran pertama dari irama Dayung Pariaman.

\section{PENUTUP}

\section{Kesimpulan}

Berdasarkan hasil pembahasan yang dibuat dalam bab empat tersebut, maka dapat disimpulkan hasilnya sebagai berikut

a. Tradisi pantun bersahut pada prinsipnya ini disajikan saat malam hari warga dan perangkat desa setempat menyebutnya sebagai malam mainangan atau inai curi, dimana malam tersebut dilakukan khusus untuk tradisi pertunjukan berbalas pantun. Tradisi ini dilakukan setelah melalui proses lamaran, surat terima hantaran, dan pengantin besanding, akad nikah, dan belaak. Barulah malamnya tradisi pantun bersahut ini dilakukan tepatnya pada pukul 20.00 WIB-23.30 WIB.

b. Fungsi pantun bersahut mainangan dalam proses adat pernikahan di Kecamatan Kaur Selatan adalah :

1. Pantun bersahut mainangan berfungsi sebagai seni berbahasa berkomunikasi yang mendidik.

2. Tradisi pantun bersahut mainangan berfungsi sebagai upaya pelestarian kebudayaan dan identitas yang dimiliki oleh masyarakat Kecamatan Kaur Selatan.

3. Berfungsi sebagai pendidikan moral

4. pantun bersahut juga berfungsi sebagai hiburan bagi masyarakat yang bisa membuat mereka tertawa, senang, dan merasa lega dan banyaklagi.

Makna berbalas pantun dibagi menjadi tiga bagian makna yaitu :

1. Makna pantun bersahut bagi pemeran ( pelaku )

Makna pantun bersahut bagi pemeran ialah sebagai pengembangan dan pelestarian budaya daerah Kecamatan Kaur Selatan, terutama dalam pengajaran nilai kehidupan yang bermoral bagi masyarakat

2. Makna pantun bersahut bagi penyelenggara ( penghajat)

Makna pantun bersahut bagi penghajat adalah sebagai bentuk wadah penghubung yang harus disampaikan maksud dan tujuan kepada individu masyarakat.

3. Makna pantun bersahut bagi penonton

Sebagai hiburan dan mendidik dalam makna yang disampaikan oleh pemeran.Tradisi pantun bersahut yang diiringi dengan tarian mainangan dan irama ini diucapkan melalui seni berkomunikasi yang sudah membudaya, dan merupakan keksahan jiwa masyarakat Kecamatan Kaur 
Selatan dan sebagai identitas budaya yang dimiliki oleh masyarakat tersebut.Faktorfaktor yang mempengaruhi memudarnya berbalas pantun mainangan Kecamatan Kaur Selatan ini adalah yang pertama kegiatan yang diadaakan sudah kuno, kemudian biaya grup pemeran yang disewa juga besar, kurang praktis pemuda kebanyakan bosan menonton seni pertunjukan tersebut dan kurang minatnya bagi pemuda untuk mempelajari tradisi pantun bersahut tersebut.

Makna teks dan konteks yang terkandung di dalam tradisi berbalas pantun mainangan ini adalah agar kita selalu beradap dalam kehidupan bersosial dan bermasyarakat serta terlebih lagi dalam berkomunikasi yang baik dan sopan dalam pengguna bahasanya.

\section{Saran}

Berdasarkan kesimpulan tersebut maka saran yang diberikan bagi penulis ialah sebagai berikut :

a. Berbalas pantun mainang sebagai salah satu bagian dari tradisi kebudayaan yang perlu dilestarikan dan dikembangkan bagi masyarakat setempat. Karena berbalas pantun dalam penyelenggaraannya ini banyak mengandung ajaran-ajaran yang berkenaan dengan tradisi pantun yang ada di Kecamatan Kaur Selatan ini. b. Agar nilai-nilai budi pekerti yang terkandung didalam berbalas pantun ini tetap terpelihara, diharapkan bagi grup tradisi pantun bersahut mainangan yang ada di Kecamatan Kaur Selatan ini sehingga dapat mendorong pemuda untuk mempelajari dan menyenangi tradisi yang ada dalam adat pernikahan tersebut.

c. Ajaran-ajaran yang disampaikan baik dalam teks maupun konteks berbalas pantun mainang Kecamatan Kaur Selatan ini dapat diterapkan dan dipelajari bagi masyarakat setempat dalam berkehidupan baik dari masyarakat pendukung maupun pembacanya.

\section{DAFTAR PUSTAKA}

Danandjaja, James. 1994. Folklor Indonesia IImu Gosip, Dongeng, dan lain-lain. Jakarta: PT Utama Grafiti.

Emzir, dan Rohman S. 2015. Teori Pengajaran Sastra. Jakarta: Rajawali Pers.

Koentjaraningrat. 1998. Kebudayaan Mentalitas dan Pembangunan. Jakarta: Aksara Baru.

Spradley, P. James. 1997. Metode Etnografi. Yogyakarta: PT. Tiara Wacana Yogya.

Rafiek, M. 2012. Teori Sastra: Kajian Teori dan Praktik. Bandung: PT Refika Aditama. 